Article

\title{
Quartz Crystal Microbalance Humidity Sensors Based on Structured Graphene Oxide Membranes with Magnesium Ions: Design, Mechanism and Performance
}

\author{
Ruobing Yi ${ }^{1}$, Bingquan Peng ${ }^{2,3}$, Yimin Zhao ${ }^{1}$, Dexi Nie ${ }^{1}$, Liang Chen ${ }^{4}$ and Lei Zhang ${ }^{1, *(D)}$ \\ 1 MOE Key Laboratory for Nonequilibrium Synthesis and Modulation of Condensed Matter, School of Physics, \\ Xi'an Jiaotong University, Xi'an 710049, China; ruobing94@163.com (R.Y.); zx1959@stu.xjtu.edu.cn (Y.Z.); \\ niedexi19970709@stu.xjtu.edu.cn (D.N.) \\ 2 Wenzhou Institute, University of Chinese Academy of Sciences, Wenzhou 325001, China; pengbq@ucas.ac.cn \\ 3 Oujiang Laboratory (Zhejiang Lab for Regenerative Medicine, Vision and Brain Health), \\ Wenzhou 325001, China \\ 4 School of Physical Science and Technology, Ningbo University, Ningbo 315211, China; liang_chen05@126.com \\ * Correspondence: zhangleio@xjtu.edu.cn
}

check for updates

Citation: Yi, R.; Peng, B.; Zhao, Y.; Nie, D.; Chen, L.; Zhang, L. Quartz Crystal Microbalance Humidity Sensors Based on Structured Graphene Oxide Membranes with Magnesium Ions: Design, Mechanism and Performance. Membranes 2022, 12, 125. https://doi.org/10.3390/ membranes12020125

Academic Editor: Yuhe Cao

Received: 25 December 2021

Accepted: 17 January 2022

Published: 21 January 2022

Publisher's Note: MDPI stays neutral with regard to jurisdictional claims in published maps and institutional affiliations.

Copyright: () 2022 by the authors. Licensee MDPI, Basel, Switzerland. This article is an open access article distributed under the terms and conditions of the Creative Commons Attribution (CC BY) license (https:// creativecommons.org/licenses/by/ $4.0 /)$.

\begin{abstract}
The application of graphene oxide (GO)-based membranes combined with a quartz crystal microbalance $(\mathrm{QCM})$ as a humidity sensor has attracted great interest over the past few years. Understanding the influence of the structure of the GO membrane (GOM) on the adsorption/desorption of water molecules and the transport mechanism of water molecules in the membrane is crucial for development of applications using GOM-based humidity sensors. In this paper, by investigating the effects of oxygen-containing groups, flake size and interlayer spacing on the performance of humidity sensing, it was found that humidity-sensing performance could be improved by rational membranestructure design and the introduction of magnesium ions, which can expand the interlayer spacing. Therefore, a novel HGO\&GO\& $\mathrm{Mg}^{2+}$ structure prepared by uniformly doping magnesium ions into GO\&HGO thin composite membranes was designed for humidity sensing from $11.3 \% \mathrm{RH}$ to $97.3 \%$ $\mathrm{RH}$. The corresponding sensor exhibits a greatly improved humidity sensitivity $(\sim 34.3 \mathrm{~Hz} / \% \mathrm{RH})$ compared with the original pure GO-based QCM sensor $(\sim 4.0 \mathrm{~Hz} / \% \mathrm{RH})$. In addition, the sensor exhibits rapid response/recovery times $(7 \mathrm{~s} / 6 \mathrm{~s})$, low hysteresis $(\sim 3.2 \%)$, excellent repeatability and good stability. This research is conducive to understanding the mechanism of GOM-based humidity sensors. Owing to its good humidity-sensing properties, the HGO\&GO\& $\mathrm{Mg}^{2+}$ membrane-based QCM humidity sensor is a good candidate for humidity sensing.
\end{abstract}

Keywords: humidity sensor; graphene oxide; interlayer spacing; response-frequency shift; response/ recovery time

\section{Introduction}

There is an increasing demand for high-precision and sensitive real-time humidity detection, which is important not only for traditional industries, such as agriculture [1], grain storage [2] and industrial production, but also for high-tech industries, such as semiconductor technology, huma-health real-time detection and clean energy storage [3,4]. QCMs have the ability to monitor mass changes at the sub-nanogram level [5-7], as well as convert the dynamic-adsorption mass change of thin membranes deposited on electrodes into resonance-frequency-shift information [8,9]. These virtues are required in humidity sensors.

The materials coating a QCM are the key to determining the detection performance of QCM-based humidity sensors [10,11]. Various materials, such as two-dimensional (2D) materials [11,12], polyelectrolytes [13] and metal oxides [14], have been researched. Among them, 2D GO materials have attracted much attention because of their many features, 
such as a high specific surface area, a high mechanical modulus, easy stacking, easy functionalization and luxuriant oxygen-containing functional groups [15-18]. However, previous studies [19] found that the interlayer spacing of GOMs is $12.8 \pm 0.2 \AA$, even when completely immersed in water. Considering that interlayer spacing of GOMs at ambient humidity is $\sim 8 \AA$, this limits the maximum sensitivity of GO-based QCM humidity sensors. In addition, the drawback of easy swelling in the wet state arises from an increase in humidity hysteresis [20-22]. Therefore, there have been many efforts in recent years to improve the humidity-sensing performance of GO-based sensors by cross-linking $\mathrm{GO}$ with hydrophilic materials, such as polymers [23], metal oxides [14] and nanodiamonds [24].

In this work, considering the complex structure of GO $[15,25]$, it is speculated that the performance of GO-based humidity sensors is affected not only by the hydrophilic strength of the material itself but also the size of the GO flakes, the interlayer spacing, and the self-assembly method of GO flakes. To determine this, the influence of oxygen content and flake size on GO-based humidity-sensing performance was first investigated, and it was found that HGO with a higher oxygen content and smaller sheet size had better humidity sensitivity. GO and HGO were prepared by Hummer's method at a low temperature and a high temperature [26], respectively. The flake size of GO was larger than that of HGO, while the oxygen content of GO was lower than that of HGO. To further explore the effect of interlayer spacing, magnesium ions were introduced into the GOM and HGOM [19,27]. According to a previous report [19], $\mathrm{Mg}^{2+}$ can not only prevent $\mathrm{GO}$ from dissolving but also expand the interlayer spacing of GO. Our results show that the introduction of magnesium ions remarkably improved the sensor performance of GO- and HGO-based humidity sensors. In addition, a reasonable composite membrane structure (composed of $\mathrm{HGO}$ and GO) can further balance the humidity sensitivity and response/recovery rate. Eventually, the obtained structure (HGO\&GO\& $\mathrm{Mg}^{2+}$ ) exhibited excellent humidity-sensing properties, showing vast potential for practical applications in the area of humidity sensors.

Humidity-sensing properties, such as sensitivity, repeatability, stability and response/ recovery time, were investigated by a QCM. In addition, to understand the mechanism of the high-humidity-sensing performance of HGO\&GO\& $\mathrm{Mg}^{2+}$-based QCM sensors, characterization was performed by atomic force microscopy (AFM), scanning electron microscopy (SEM), energy dispersive X-ray (EDX) spectroscopy, X-ray diffraction (XRD), Fourier transform infrared (FTIR) spectroscopy and X-ray photoelectron spectroscopy (XPS).

\section{Materials and Methods}

\subsection{Materials}

Graphite powder (325 mesh), sulphuric acid $\left(\mathrm{H}_{2} \mathrm{SO}_{4}\right)$, potassium persulfate $\left(\mathrm{K}_{2} \mathrm{~S}_{2} \mathrm{O}_{8}\right)$, phosphorus pentoxide $\left(\mathrm{P}_{2} \mathrm{O}_{5}\right)$, potassium permanganate $\left(\mathrm{KMnO}_{4}\right)$, hydrogen peroxide $\left(\mathrm{H}_{2} \mathrm{O}_{2}\right)$, magnesium chloride $\left(\mathrm{MgCl}_{2}\right)$ and hydrochloric acid $(\mathrm{HCl})$ were used in this research. All chemical regents were purchased from Sinopharm Chemical Reagent Co. (Shanghai, China) and used with ultra-pure deionized (DI) water with $18.2 \mathrm{M} \Omega \cdot \mathrm{cm}^{-1}$ in all experiments. All the reagents were utilized as received, without further purification.

\subsection{Preparation of $G O$ and $H G O$ Suspension}

GO aqueous suspension $(5 \mathrm{mg} / \mathrm{mL})$ was prepared according to the modified hummers method, as previously reported $[19,28]$. Graphite powder was added to concentrated $\mathrm{H}_{2} \mathrm{SO}_{4}, \mathrm{~K}_{2} \mathrm{~S}_{2} \mathrm{O}_{8}$ and $\mathrm{P}_{2} \mathrm{O}_{5}$ solution and stirred continuously at $80{ }^{\circ} \mathrm{C}$ for $4.5 \mathrm{~h}$. The mixture was purified by vacuum filtration and washed with deionized (DI) water. After vacuum drying at $60{ }^{\circ} \mathrm{C}$ overnight, oxidized graphite was obtained. The obtained oxidized graphite was further oxidized in concentrated $\mathrm{H}_{2} \mathrm{SO}_{4}$ and $\mathrm{KMnO}_{4}$ at constant temperatures of 6 and $60{ }^{\circ} \mathrm{C}$, respectively. The solutions were stirred at $35^{\circ} \mathrm{C}$ for $2 \mathrm{~h}$, and then they were diluted with $250 \mathrm{~mL}$ DI water at 40 and $80^{\circ} \mathrm{C}$, respectively. The graphene oxide prepared at higher temperatures (oxidized at $60^{\circ} \mathrm{C}$ and adding DI water at $80^{\circ} \mathrm{C}$ ) was named $\mathrm{HGO}$, while the other one was named as GO. The solutions were further stirred at room temperature for $2 \mathrm{~h}$, and $\mathrm{H}_{2} \mathrm{O}_{2}(30 \%, 20 \mathrm{~mL})$ was added immediately after dilution with DI water $(700 \mathrm{~mL})$. 
The product was centrifuged and sequentially washed with a 1:10 aqueous $\mathrm{HCl}$ solution and DI water to remove impurities. Finally, the GO and HGO aqueous suspension with a concentration of about $5 \mathrm{mg} / \mathrm{mL}$ was prepared. The mixed solution of GO and HGO (GO\&HGO) suspension was obtained by mixing equal volumes of $\mathrm{HGO}$ and GO solutions with same concentration $(5 \mathrm{mg} / \mathrm{mL})$.

\subsection{Sensor Fabrication}

QCM devices (Model 922A, Princeton Applied Research, Oak Ridge, TN, USA) consisting of AT-cut quartz crystals ( $8 \mathrm{~mm}$ diameter) with a fundamental resonance frequency of $9 \mathrm{MHz}$ and Pt electrodes (SEIKO EG\&G Co., Ltd., Tokyo, Japan) on both sides were employed in this research. Before the preparation of thin sensing membranes, all QCM devices were washed successively with diluted hydrochloric acid, deionized water and ethanol, and each process was followed by a drying procedure at $70^{\circ} \mathrm{C}$ for $30 \mathrm{~min}$. The GO, HGO and GO\&HGO sheets were deposited by drop-casting $10 \mu \mathrm{L}$ of the corresponding suspension with a concentration of $0.1 \mathrm{mg} \mathrm{mL}^{-1}$ onto the Pt surface of the QCM electrode and drying at $70{ }^{\circ} \mathrm{C}$ for $2 \mathrm{~h}$, as illustrated in Figure 1. The GO (HGO, HGO\&GO)-coated Pt electrode was immersed in $1.5 \mathrm{~mL}$ of $0.1 \mathrm{M} \mathrm{MgCl}_{2}$ at $25^{\circ} \mathrm{C}$ for $2 \mathrm{~h}$ and was measured after drying at $70{ }^{\circ} \mathrm{C}$ for $1 \mathrm{~h}$ to improve the adhesion properties of the GOM on the Pt electrode.

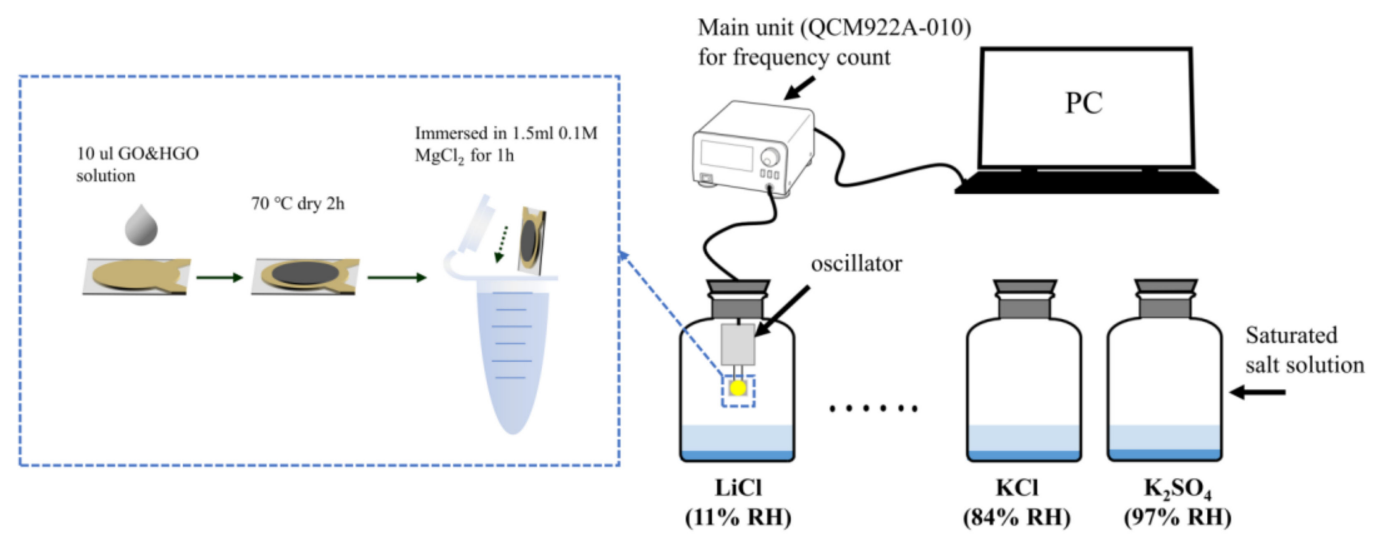

Figure 1. Schematic images of the preparation process of the HGO\&GO\&Mg ${ }^{2+}$-based quartz crystal microbalance (QCM) sensor and the humidity-sensing experimental setup.

\subsection{Measurement of Relative-Humidity-Sensing Performance and Characterization}

The schematic of the experimental system used for relative-humidity (RH)-sensing measurement is illustrated in Figure 1. Measurements were collected at an ambient temperature of $25{ }^{\circ} \mathrm{C}$. Saturated solutions of $\mathrm{LiCl}, \mathrm{CH}_{3} \mathrm{COOK}, \mathrm{MgCl}_{2}, \mathrm{~K}_{2} \mathrm{CO}_{3}, \mathrm{Mg}\left(\mathrm{NO}_{3}\right)_{2}$, $\mathrm{NaCl}, \mathrm{KCl}$ and $\mathrm{K}_{2} \mathrm{SO}_{4}$ at $25^{\circ} \mathrm{C}$ provided $11 \%, 23 \%, 33 \%, 43 \%, 52 \%, 75 \%, 85 \%$ and $97 \% \mathrm{RH}$ levels [29], respectively. The real-time frequency of the QCM sensors under different RH levels was obtained by the QCM and recorded by a computer. During the measurement process, the frequency value $\left(\mathrm{F}_{0}\right)$ of the sensor exposed to $11 \% \mathrm{RH}$ was used as the baseline to evaluate the performance of the QCM sensors. The recording periods for response and recovery times were fixed at $30 \mathrm{~s}$.

The response-frequency shift was defined as:

$$
\Delta \mathrm{F}=\mathrm{F}-\mathrm{F}_{0}
$$

where $\mathrm{F}$ and $\mathrm{F}_{0}$ are the response frequency at the corresponding tested $\mathrm{RH}$ level and $11 \% \mathrm{RH}$, respectively. The humidity hysteresis is an important criterion for practical application, defined as:

$$
\text { Humidity hysteresis }=\frac{\Delta \mathrm{F}_{\max }}{\mathrm{F}_{\text {total }} \times 100 \%}
$$


where $\Delta \mathrm{F}_{\max }$ is the maximum hysteresis error and $\mathrm{F}_{\text {total }}$ is the total response-frequency-shift output from minimum humidity level (11\%) to maximum humidity level (97\%).

The FTIR spectra were collected in the mid-infrared range of $4000-1000 \mathrm{~cm}^{-1}$ using a Nicolet iS50 FTIR spectrometer (Thermo Fisher Scientific, Shanghai, China), and the XPS results of free-standing GO and HGO membranes were characterized by a Thermo Fisher ESCALAB Xi+ (Thermo Fisher Scientific, Shanghai, China). XRD patterns of membranes were obtained by an X-ray diffractometer system (Bruker D8 Advance, $\lambda=0.15418 \mathrm{~nm}$; Bruker Corporation, Billerica, MA, USA). XRD spectra of membranes under different relative humidity levels were tested on a glass substrate with a cylindrical groove in the middle. Saturated solutions of different salts were added to the groove, as previously described. These saturated solutions can control the humidity. Meanwhile, the sample was placed on a glass supported by a rubber cement above the liquid level. The whole groove was sealed with plastic wrap during the entire test process. GO and HGO flakes were measured by atomic force microscopy (AFM, SPM-9700HT; Shimadzu Co., Ltd., Tokyo, Japan). SEM images were collected using a Gemini SEM 500 (Carl Zeiss Co., Ltd., Shanghai, China) series field-emission scanning electron microscope operated at an accelerating voltage of $15 \mathrm{kV}$.

\section{Results and Discussion}

\subsection{Characterization Results}

Figure 2a shows the humidity-sensing schematic of HGO\&GOM\& $\mathrm{Mg}^{2+}$. It can be clearly seen that the framework is composed of GO and HGO flakes with different lateral sizes. The AFM images in Figure 2b, c provide the details of single flakes of GO and HGO. The results show that the maximum lateral size of GO flakes (approximately 4-10 $\mu \mathrm{m}$ ) was approximately 4-10 times larger than that of HGO flakes $(\sim 1 \mu \mathrm{m})$. Therefore, smaller HGO flakes were fabricated during the process of oxidation and exfoliation at higher reaction temperatures.

(a)

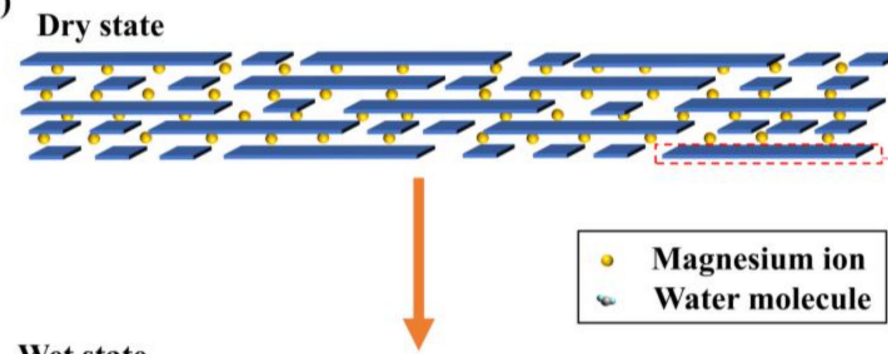

(b)

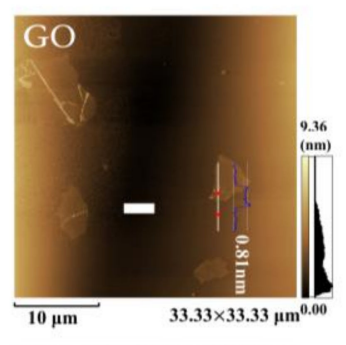

(c)

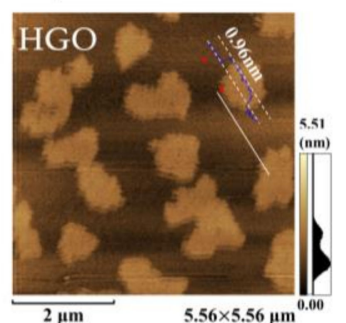

Figure 2. (a) Schematic diagram of HGO adsorption/desorption of water molecules. (b,c) Atomic Force Microscopy (AFM) images of single flakes of Graphene Oxide (GO) and HGO.

The SEM images of GOM, HGOM and HGO\&GOM, which are shown in Figure 3a-c, also prove this indirectly. It can be clearly observed that the surfaces of HGOM and HGO\&GOM were rougher and more wrinkled than those of GO. It is known that flake size and the oxygen content have a great influence on morphology [28]. As the SEM images show in Figure 3d-f, although the morphologies of GOM\&Mg ${ }^{2+}, \mathrm{HGOM}_{\mathrm{CMg}^{2+}}$ and HGO\&GOM\&Mg ${ }^{2+}$ are very similar to those of GOM, HGOM and HGO\&GOM, it is 
clear that magnesium was uniformly distributed in these membranes, according to EDX spectroscopy (Figure 3g-i). Moreover, the distribution at the fold was more concentrated.
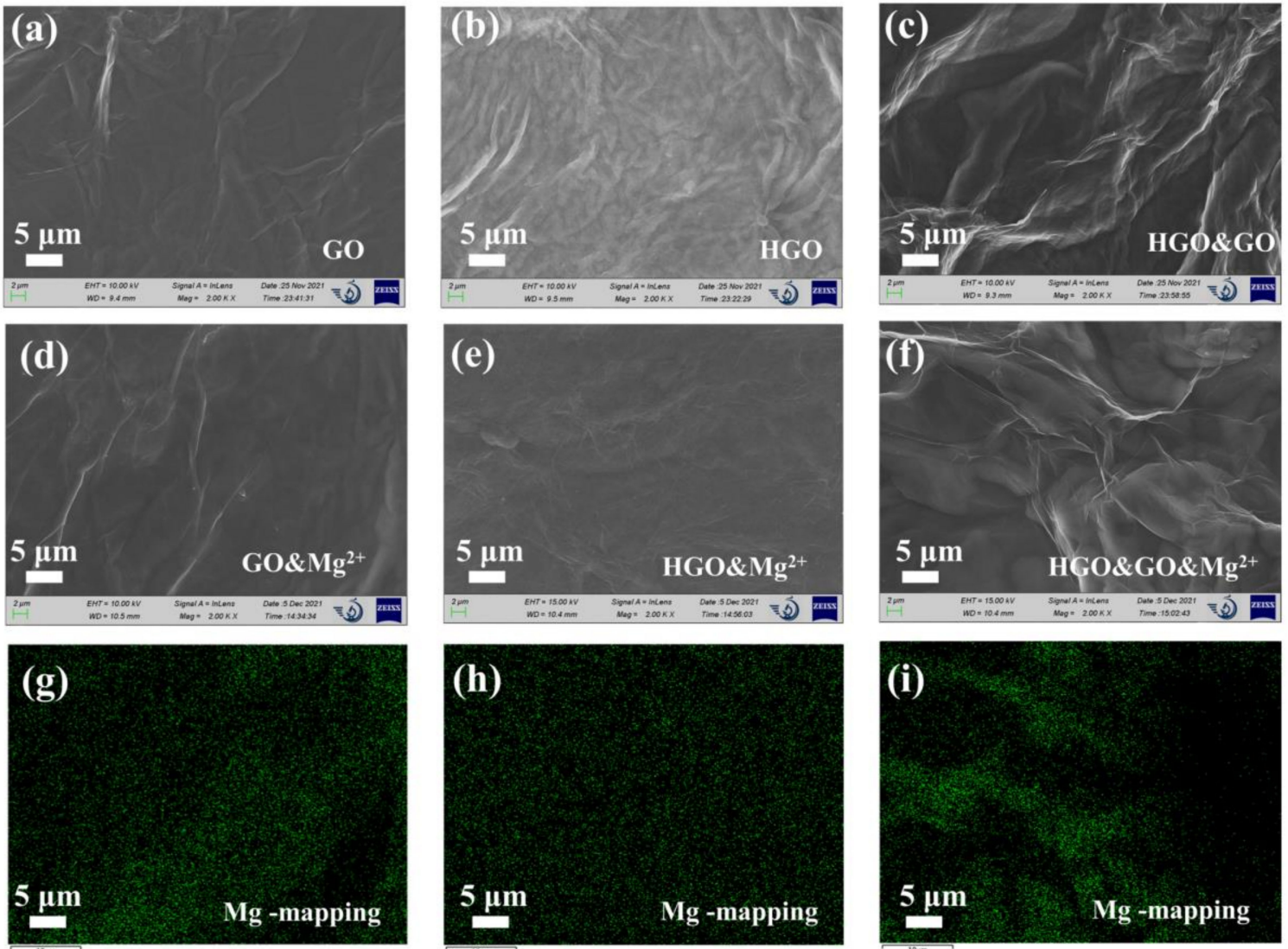

Figure 3. (a-f) Scanning Electron Microscopy (SEM) images of the GO, HGO, HGO\&GO, GO\&Mg ${ }^{2+}$, HGO\& $\mathrm{Mg}^{2+}$ and HGO\&GO\&Mg${ }^{2+}$ membranes. (g-i) Corresponding Mg elemental mapping detected in the energy dispersive $\mathrm{X}$-ray (EDX) spectra of $(\mathbf{d}-\mathbf{f})$, respectively.

The number of oxygen-containing groups in GO has a significant impact on the humidity sensitivity of GO-based humidity sensors [11]. To explore this, the FTIR spectra of GO and HGO were detected, as shown in Figure $4 \mathrm{a}$. The main characteristic peaks at $\sim 3594 \mathrm{~cm}^{-1}, 1730 \mathrm{~cm}^{-1}, 1622 \mathrm{~cm}^{-1}$ and $1116-1228 \mathrm{~cm}^{-1}$ correspond to stretching vibrations of hydroxyl $(\mathrm{O}-\mathrm{H})$ groups, carboxyl $(\mathrm{C}=\mathrm{O})$ groups, aromatic ring $(\mathrm{C}-\mathrm{C} / \mathrm{C}=\mathrm{C})$ and epoxy (C-O-C) groups [28,30,31], respectively. Obviously, the intensity of the absorption peak after normalization in GO is weaker than that in $\mathrm{HGO}$ at $3594 \mathrm{~cm}^{-1}, 1730 \mathrm{~cm}^{-1}, 1622 \mathrm{~cm}^{-1}$ and 1116-1228 $\mathrm{cm}^{-1}$, which shows that the oxygen content of the former is lower than that of the latter. It can be concluded that a high reaction temperature is beneficial for further intercalation of oxidized groups, which also promotes the exfoliation of graphite oxide into smaller GO sheets. This is identified with the results of AFM. Figure 4b,c show the full scan XPS spectra of HGO and GO. Obviously, the former contains more oxygen than the latter. As shown in Figure $4 \mathrm{c}, \mathrm{d}$ the proportion of oxygen-containing functional groups can be obtained according to $\mathrm{C} 1 \mathrm{~s}$ curve-fitting peak analysis. Four peaks at $284.6 \mathrm{eV}$, $286.7 \mathrm{eV}, 287.8 \mathrm{eV}$ and $288.9 \mathrm{eV}$ correspond to $\mathrm{C}-\mathrm{C} / \mathrm{C}=\mathrm{C}, \mathrm{C}-\mathrm{O} / \mathrm{C}-\mathrm{O}-\mathrm{C}, \mathrm{C}=\mathrm{O}$ and $\mathrm{O}-\mathrm{C}=\mathrm{O}$, respectively $[3,19,32,33]$. It can be observed that the amount of hydroxyl/epoxy in GO is lower than that in HGO, which is consistent with the FTIR results. 

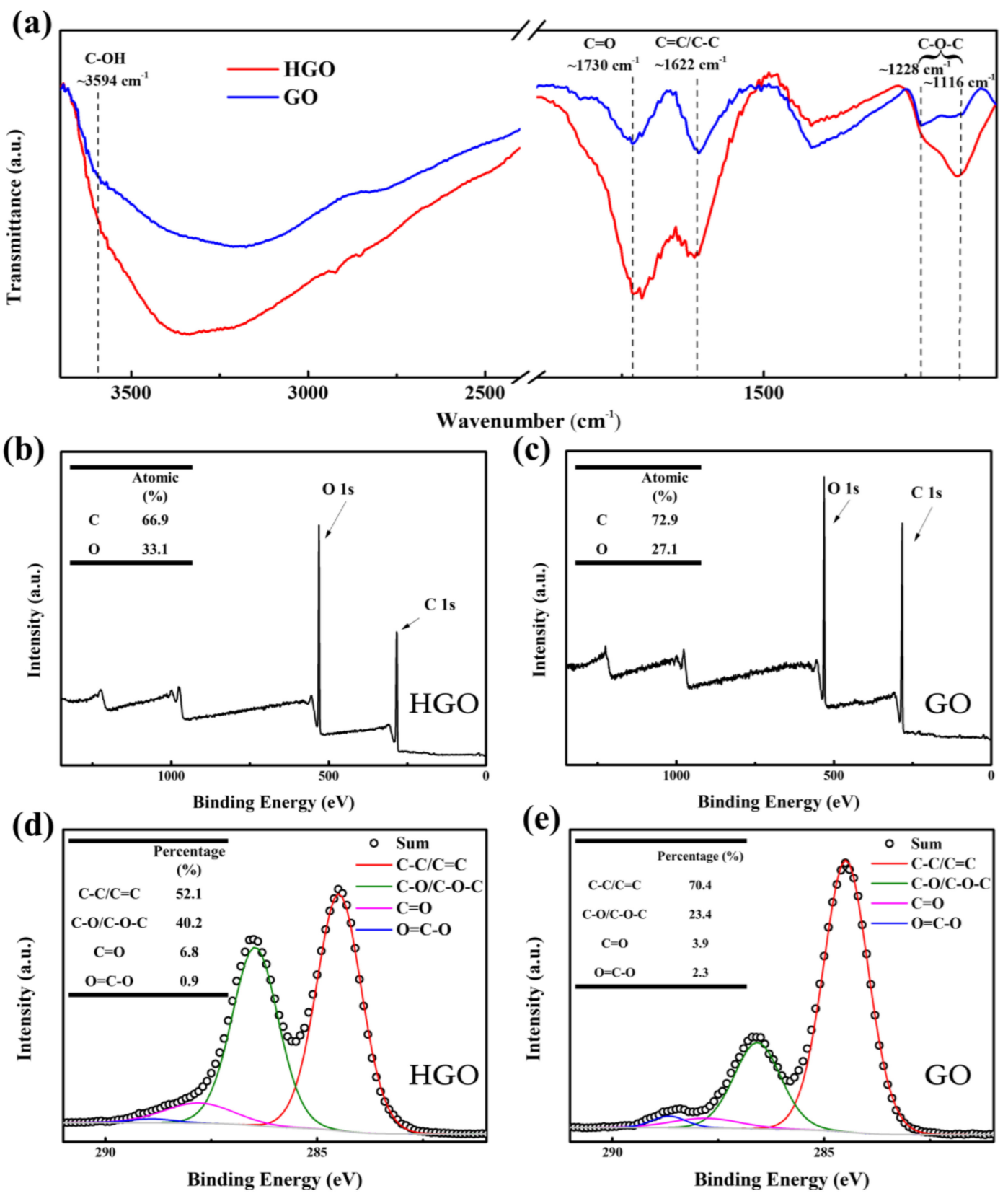

Figure 4. (a) The normalized Fourier transform infrared (FTIR) spectroscopy of GO and HGO membranes. (b,c) The full-scan X-ray photoelectron spectroscopy (XPS) of HGO and GO; inset is the atomic percentage of $\mathrm{C}$ and $\mathrm{O}$. (d,e) C1s XPS spectra of HGO and GO; inset is the proportion of oxygen-containing functional groups.

It is easily understood that the interlayer spacing of GOMs may have a direct influence on their ability to adsorb water molecules [10]. As shown in Figure 5a, the interlayer spacing of GO $(\sim 8.3 \AA)$ is greater than that of $\mathrm{HGO}(\sim 7.5 \AA)$ at ambient humidity, while that of HGO\&GO $(\sim 7.8 \AA)$ is between those of HGO and GO. Somewhat curiously, the interlayer spacing of $\mathrm{HGO}$ with higher oxygen content is less than the interlayer spacing of the lower-oxygen-content GO, probably because the stacking of smaller HGO flakes is more compact than that of the GO flakes during the self-assembly process. As shown in Figure $5 b$, the interlayer spacings of HGO\&GO\& $\mathrm{Mg}^{2+}$ under different humidity levels $(11 \%, 38 \%, 55 \%, 75 \%$ and $97 \% \mathrm{RH})$ are $7.5 \AA, 7.9 \AA, 8.5 \AA, 9.7 \AA$ and $11.7 \AA$, respectively. It can be easily observed that the interlayer spacing of HGO\&GO\&Mg ${ }^{2+}$ increases with increasing humidity. The interlayer spacing at $97 \% \mathrm{RH}$ is $\sim 4.2 \AA$ greater than that at $11 \%$ 
$\mathrm{RH}$, while the interlayer spacing of $\mathrm{HGO} \& \mathrm{GOM}$ completely immersed in $\mathrm{MgCl}_{2}$ solution is $15.3 \AA$. According to a previous report, the interlayer spacing of $\mathrm{GO}$ controlled by $\mathrm{MgCl}_{2}$ solution is $13.6 \AA$, which is less than that of the $\mathrm{HGO \& GO}$ controlled by $\mathrm{MgCl}_{2}$ solution obtained in this work. From the full-width half maximum (FWHM) of the characteristic peak, $\mathrm{MgCl}_{2}$-solution-controlled GOM exhibits a greater degree of lamellar orientation, which is consistent with our previous report [19]. Since the XRD test under controlled humidity conditions requires a layer of cling film (to keep enclosure space, as shown in Figure $5 c$ on the surface of the HGO\&GO membranes, it can be seen in Figure $5 b$ that all the signals are weak and have a large FWHM, except for the XRD peak of $\mathrm{MgCl}_{2}$-solutionimmersed HGO\&GOM. In summary, HGO\&GO\&Mg ${ }^{2+}$ possesses a large interlayer spacing and a greater degree of lamellar orientation, which may be beneficial for the adsorption capacity of water molecules and the transport rate of water molecules inside the membrane.

(a)

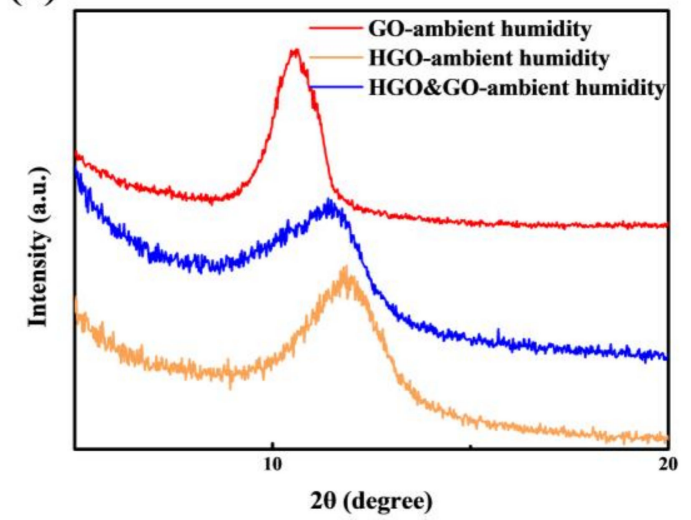

(b)

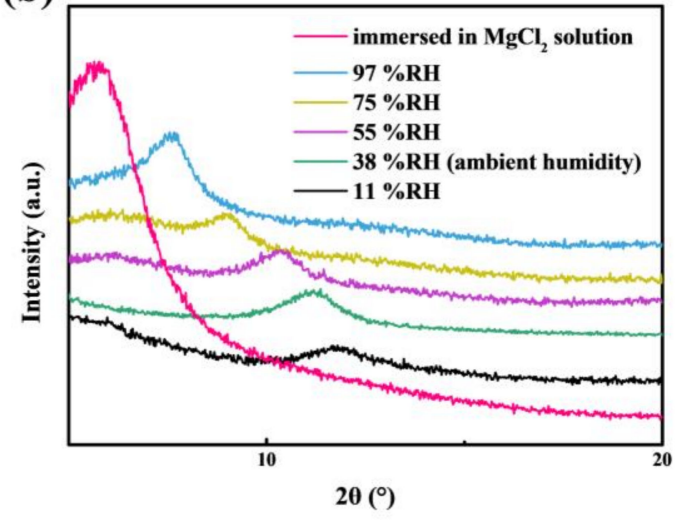

(c)
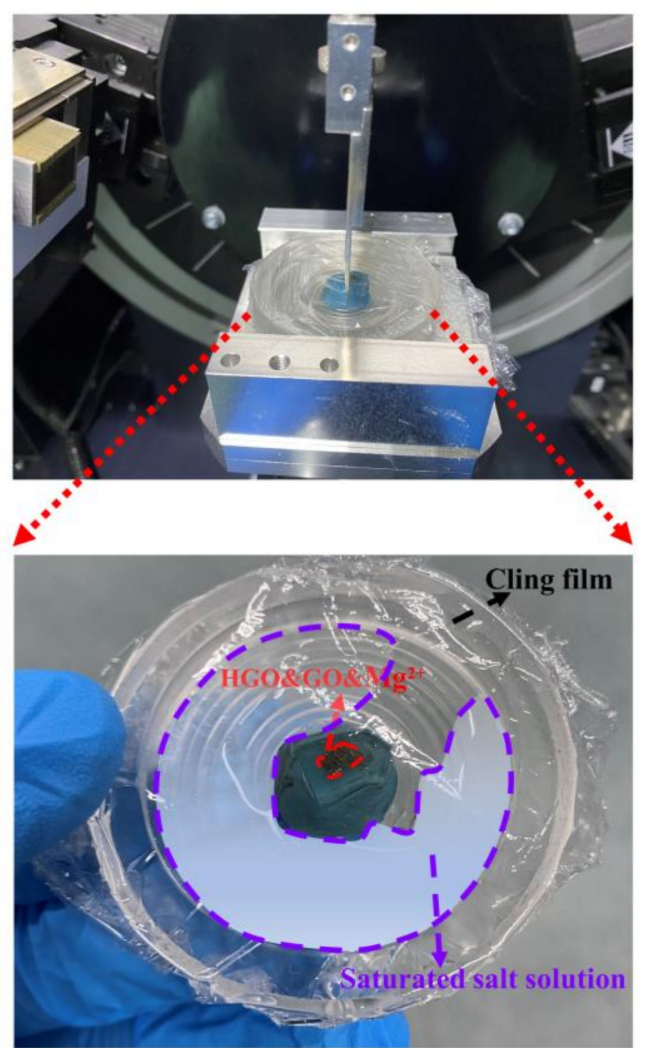

Figure 5. (a) X-ray diffraction (XRD) spectroscopy of dry GO, HGO and HGO\&GO membranes. (b) XRD spectra of HGO\&GO\& $\mathrm{Mg}^{2+}$ membranes under different relative humidity levels and HGO\&GO membranes immersed in $\mathrm{MgCl}_{2}$ solution. (c) Images of the substrate for controlling humidity used in XRD detection.

\subsection{Humidity-Sensing Properties}

The response-frequency shifts $(\Delta \mathrm{F})$ of the GO- and HGO-based sensors with increasing $\mathrm{RH}$ levels in the range of $11-97 \% \mathrm{RH}$ are shown in Figure $6 \mathrm{a}, \mathrm{b}$. It can be clearly found that the response, $\Delta \mathrm{F}$, of the two sensors both increase with increasing humidity. The maximum response, $\Delta \mathrm{F}$, of HGO- and GO-based sensors were $232 \mathrm{~Hz}$ and $793 \mathrm{~Hz}$, respectively, in the relative humidity range from 11 to $97 \% \mathrm{RH}$. The response, $\Delta \mathrm{F}$, of the HGO-based sensor was greater than that of the GO-based sensor, suggesting that a smaller flake size and higher oxygen content are conducive to absorbing water molecules. This performance is consistent with that observed in previous works [34]. Moreover, the GO\& $\mathrm{Mg}^{2+}$ - and $\mathrm{HGO}_{\mathrm{C}} \mathrm{Mg}^{2+}$ based sensors both exhibit significant strengthening in response, $\Delta \mathrm{F}$, compared with the 
GO- and HGO-based sensors. Although the response, $\Delta \mathrm{F}$, of the GO\&Mg${ }^{2+}$-based sensor $(19.6 \mathrm{~Hz} / \% \mathrm{RH})$ is not as high as that of the HGO\& $\mathrm{Mg}^{2+}$-based sensor $(52.7 \mathrm{~Hz} / \% \mathrm{RH})$, the former still increased to approximately 10 times that of the original GO-based sensor. Because the size of GO flakes is too large and the oxygen-content is low, it is difficult for water molecules to enter the deep area when GO is not completely wet. Therefore, the interior of GO membranes may not be fully utilized. The introduction of $\mathrm{Mg}^{2+}$ increases the interlayer spacing of the GO and makes it easier for water to enter, while this has a relatively smaller effect on HGO. This is in agreement with the XRD results. In addition, the evenly distributed $\mathrm{Mg}^{2+}$ ions have a certain degree of hydrophilicity [35-37], which is also beneficial for improvement in the response, $\Delta \mathrm{F}$.

(a)

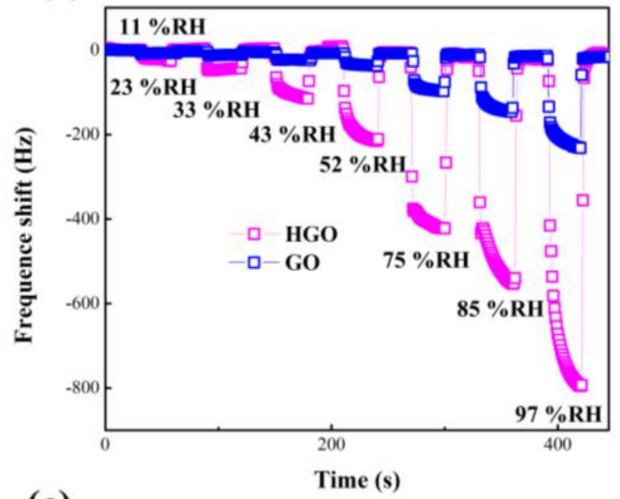

(c)

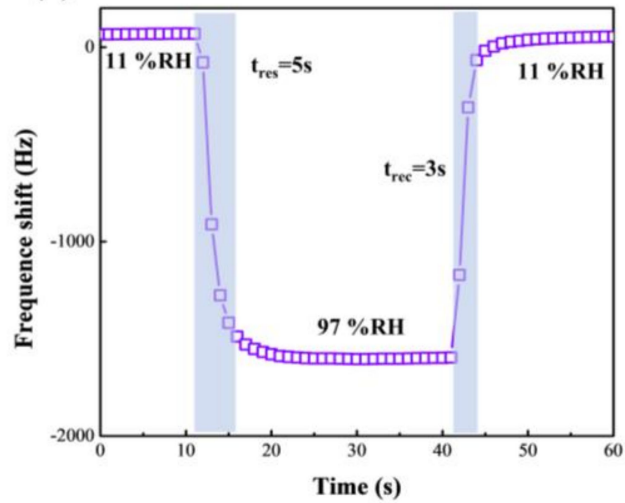

(b)

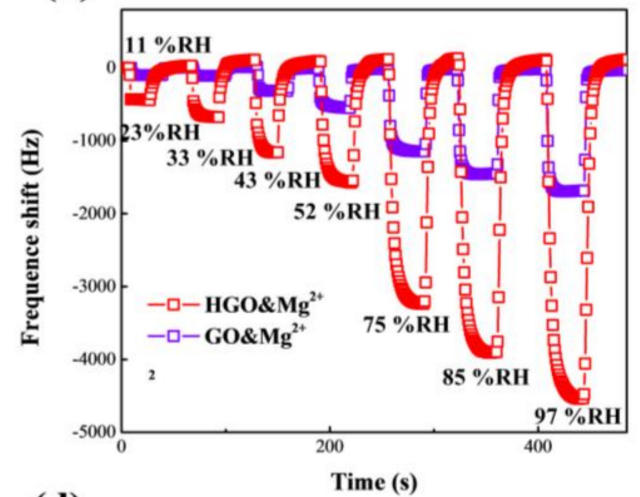

(d)

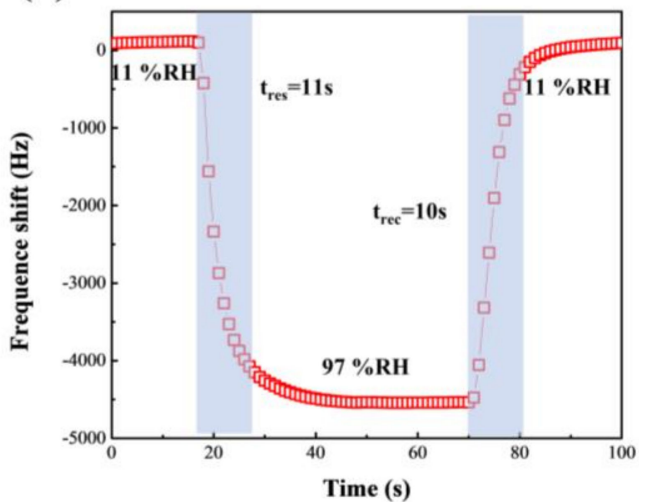

Figure 6. (a) Response-frequency shift of HGO- and GO-based QCM humidity sensors with relative-

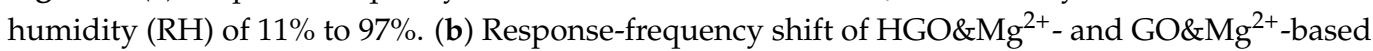

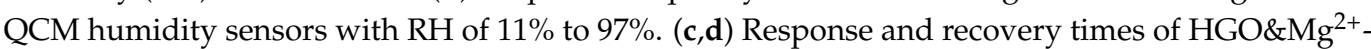
and GO\& $\mathrm{Mg}^{2+}$-based QCM humidity sensors, respectively, switching from $11 \% \mathrm{RH}$ to $97 \% \mathrm{RH}$.

To assess the dynamic response performance of the sensors, the response and recovery times between $11 \% \mathrm{RH}$ and $97 \% \mathrm{RH}$ were also measured. Response and recovery time $\left(t_{\text {res }}\right.$ and $\left.t_{\text {rec }}\right)$ in this work is defined as the time for the response, $\Delta F$, to achieve $90 \%$ of the total $\Delta \mathrm{F}$ amount between two different humidity levels, respectively, during the process of adsorption and desorption. As shown in Figure $6 \mathrm{c}, \mathrm{d}$, the GO\& $\mathrm{Mg}^{2+}$-based sensor presents a shorter $t_{\text {res }} / t_{\text {rec }}(5 \mathrm{~s} / 3 \mathrm{~s})$ than the HGO\&Mg ${ }^{2+}$-based sensor $(11 \mathrm{~s} / 10 \mathrm{~s})$. The reason is that on one hand, the response, $\Delta \mathrm{F}$, of GO is relatively smaller, and on the other hand, the large area of $\mathrm{sp}^{2}$ hydrophobic channels in the GO membrane can help oxygen-containing groups and $\mathrm{Mg}^{2+}$ ions more quickly absorb and desorb water molecules [38-40]. Considering that the combination of $\mathrm{HGO}$ with $\mathrm{Mg}^{2+}$ can greatly improve the response-frequency shift and $\mathrm{GO}$ with $\mathrm{Mg}^{2+}$ can decrease response/recovery time of the QCM sensor, respectively, a more practical sensor may be prepared by combining $\mathrm{HGO}, \mathrm{GO}$ and $\mathrm{Mg}^{2+}$.

The response, $\Delta \mathrm{F}$, humidity hysteresis and $t_{\text {res }} / t_{\text {rec }}$ of the HGO\&GO\&Mg ${ }^{2+}$-based sensor were further measured to evaluate its humidity-sensing performance, as shown in 
Figure 7. It is easily observed that the performance of the HGO\&GO\& $\mathrm{Mg}^{2+}$-based sensor shows a remarkable strengthening compared with the HGO\&GO-based sensor, suggesting that $\mathrm{MgCl}_{2}$ plays an important role in improving the humidity-sensing ability. The response, $\Delta \mathrm{F}$, of the HGO\&GO\& $\mathrm{Mg}^{2+}$-based sensor $(34.3 \mathrm{~Hz} / \% \mathrm{RH})$ decreased compared to that of $\mathrm{HGO}_{\mathrm{N}} \mathrm{Mg}^{2+}(52.7 \mathrm{~Hz} / \% \mathrm{RH})$, while the $\mathrm{t}_{\text {res }}$ and $\mathrm{t}_{\text {rec }}$ of the former were reduced to $7 \mathrm{~s}$ and $6 \mathrm{~s}$, respectively. Figure $7 \mathrm{c}$ shows the dynamic response, $\Delta \mathrm{F}$, of the humidification process (from $11 \% \mathrm{RH}$ to $97 \% \mathrm{RH}$ ), corresponding to the absorption of water molecules, and the dehumidification process (from $97 \% \mathrm{RH}$ to $11 \% \mathrm{RH}$ ), corresponding to the desorption of water molecules. The difference between the two processes is shown in Figure $7 \mathrm{~d}$. The maximum $\Delta \mathrm{F}$ difference between the absorption and desorption processes is only $96 \mathrm{~Hz}$, which corresponds to a humidity hysteresis of only $~ 3.2 \mathrm{RH} \%$. The humidity hysteresis is calculated according to Equations (1) and (2). The reason for such a low humidity hysteresis is that $\mathrm{Mg}^{2+}$ can effectively limit the swelling of GO [19]. These results suggest good reversibility between the humidification and dehumidification processes.

(a)

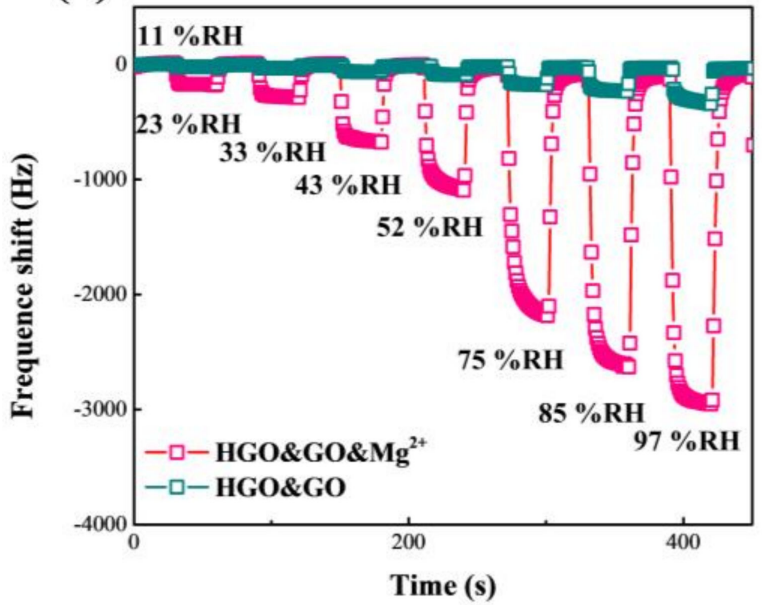

(c)

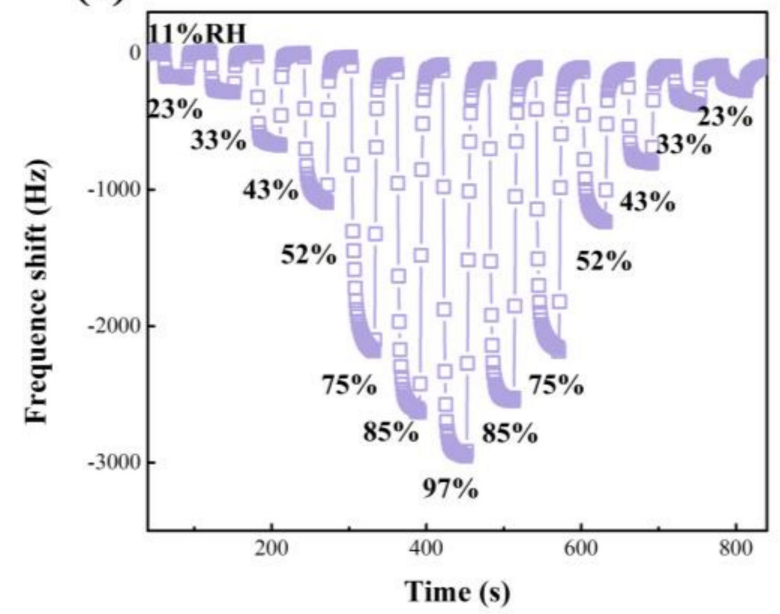

(b)

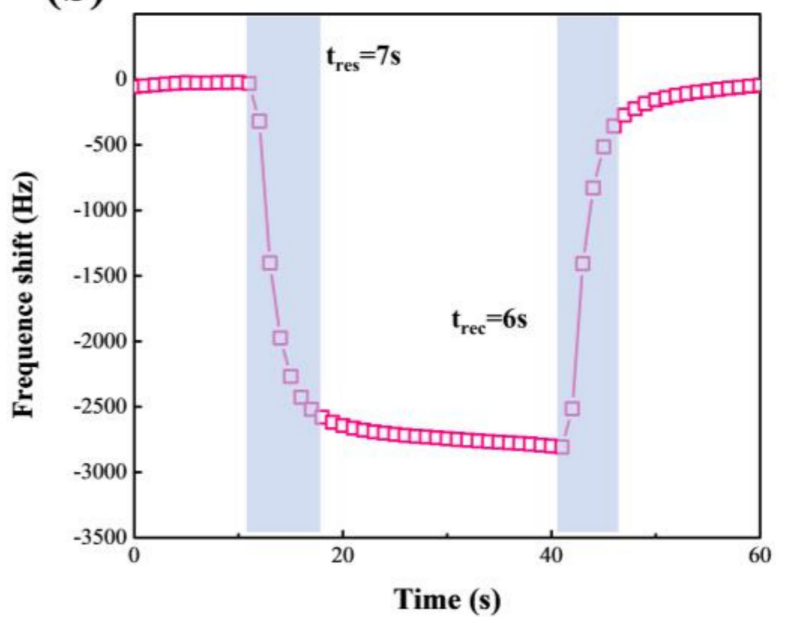

(d)

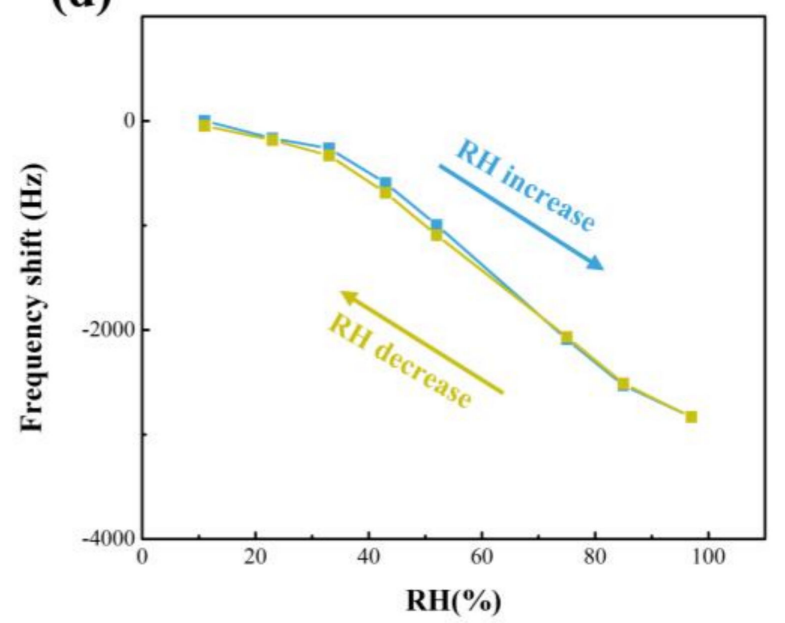

Figure 7. (a) Response-frequency shift of HGO\&GO- and HGO\&GO\&Mg ${ }^{2+}$-based QCM humidity sensors with RH of $11 \%$ to $97 \%$. (b) Response-frequency shift of HGO\&GO\&Mg ${ }^{2+}$-based QCM humidity sensors with RH of $11 \%$ to $97 \%$. The dynamic humidity hysteresis loop (c) and the humidity hysteresis curve (d) versus time for HGO\&GO\& $\mathrm{Mg}^{2+}$-based QCM humidity sensors with RH of $11 \%$ to $97 \%$.

Table 1 shows the comparison of humidity sensing between the GO-based humidity sensors obtained in this work and previous works. “@90\% RH (1-97\%RH)” means the humidity range for testing reaction/recovery times in this work ranges from 11 to $97 \%$, and 
the response and recovery times are defined as the time for the response, $\Delta \mathrm{F}$, to achieve $90 \%$ of the total amount during the processes of adsorption and desorption, respectively. In this situation, it is apparent that the HGO\&GO\&Mg ${ }^{2+}$-based QCM sensor is better than most GO-based QCM sensors not only in terms of sensitivity but also in response/recovery time. The HGO\&GO\& $\mathrm{Mg}^{2+}$-based QCM sensor is also excellent, even compared to other materials used for humidity sensors.

Table 1. Comparison between recently reported QCM humidity sensors and this work.

\begin{tabular}{|c|c|c|c|c|c|}
\hline Materials & $\begin{array}{l}\text { Sensing } \\
\text { Range } \\
\text { (\%RH) }\end{array}$ & $\begin{array}{l}\text { Sensitivity } \\
\text { (Hz/\%RH) }\end{array}$ & $\begin{array}{l}\text { Response/Recover } \\
\text { Time } \\
\text { (s) }\end{array}$ & $\begin{array}{c}\text { Published } \\
\text { Year }\end{array}$ & Ref \\
\hline RGO-PEO & $0-84$ & 20 & $\begin{array}{c}11 \mathrm{~s} / 7 \mathrm{~s} @ 63.2 \% \mathrm{RH} \\
(0-84 \% \mathrm{RH})\end{array}$ & 2018 & [41] \\
\hline PANI/GO & $0-97$ & 20 & $\begin{array}{c}8 \mathrm{~s} / 5 \mathrm{~s} @ 63.2 \% \mathrm{RH} \\
(0-97 \% \mathrm{RH})\end{array}$ & 2018 & [13] \\
\hline $\mathrm{GO} / \mathrm{C}_{60}$ & $11-97$ & 31 & $\begin{array}{c}72 \text { s/8 s@90\% RH } \\
(0-97 \% \text { RH) }\end{array}$ & 2018 & [42] \\
\hline $\mathrm{GO} / \mathrm{SnO}_{2} / \mathrm{PANI}$ & 0-97 & 29.1 & $\begin{array}{c}7 \text { s } / 2 \text { s@63.2\% RH } \\
(0-97 \% R H)\end{array}$ & 2018 & [43] \\
\hline $\mathrm{GO}$ & $10-90$ & 5.6 & not given & 2020 & [34] \\
\hline $\mathrm{GO}$ & $10-70$ & 10.9 & not given & 2019 & [44] \\
\hline $\mathrm{MoS}_{2} / \mathrm{GO} / \mathrm{C}_{60}-\mathrm{OH}$ & $2-97$ & 31.8 & $\begin{array}{c}1.3 \mathrm{~s} / 1.2 \mathrm{~s} @ 90 \% \mathrm{RH} \\
(54-97 \% \mathrm{RH})\end{array}$ & 2021 & [10] \\
\hline $\mathrm{PAN} / \mathrm{PEI}$ & $38-78$ & 154.5 & $\begin{array}{c}13 \text { s } / 7 \text { s@90\% RH } \\
(38-78 \% \text { RH })\end{array}$ & 2020 & [45] \\
\hline MXene nanosheets & $11-97$ & 12.8 & $\begin{array}{c}6 \mathrm{~s} / 2 \mathrm{~s} @ 90 \% \mathrm{RH} \\
(11-97 \% \mathrm{RH})\end{array}$ & 2021 & [46] \\
\hline $\mathrm{PPy} / \mathrm{CS}$ & $0-97$ & 52.9 & $\begin{array}{c}13 \text { s } / 2 \text { s@90\% RH } \\
(0-97 \% \text { RH) }\end{array}$ & 2021 & [47] \\
\hline $\mathrm{GO}_{\mathrm{Mg}^{2+}}$ & $11-97$ & 19.6 & $\begin{array}{c}5 \mathrm{~s} / 3 \mathrm{~s} @ 90 \% \mathrm{RH} \\
(11-97 \% \mathrm{RH})\end{array}$ & 2021 & This work \\
\hline 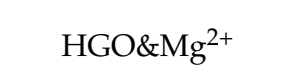 & $11-97$ & 52.7 & $\begin{array}{c}11 \text { s } / 10 \text { s@90\% RH } \\
(11-97 \% \text { RH) }\end{array}$ & 2021 & This work \\
\hline HGO\&GO\&Mg ${ }^{2+}$ & $11-97$ & 34.3 & $\begin{array}{c}7 \text { s } / 6 \text { s@90\% RH } \\
(11-97 \% \text { RH) }\end{array}$ & 2021 & This work \\
\hline
\end{tabular}

“@x \% RH ( $y-z \% \mathrm{RH})$ " means the humidity range for testing reaction/recovery times in this work from $y$ to $z \%$ $\mathrm{RH}$. The response and recovery times are defined as the time for the response, $\Delta \mathrm{F}$, to achieve $x \%$ of the total $\Delta \mathrm{F}$ amount between two different humidity levels during the processes of adsorption and desorption, respectively.

Stability and repeatability are two important criteria to measure the practical value of humidity-sensor performance. Figure 8 a shows the repeatability of the HGO\&GO\& $\mathrm{Mg}^{2+}$ based sensor for different humidity levels: $11 \%$ to $33 \%$ RH and $52 \%$ to $97 \% \mathrm{RH}$. There is no clear variation in the response, $\Delta \mathrm{F}$, under the same humidity conversion conditions, suggesting that the HGO\&GO\& $\mathrm{Mg}^{2+}$-based sensor has excellent repeatability. In addition, as observed in Figure $8 \mathrm{~b}$, the response, $\triangle \mathrm{F}$ of the HGO\&GO\&Mg${ }^{2+}$-based sensor at three humidity levels ( $33 \% \mathrm{RH}, 52 \% \mathrm{RH}$ and $97 \% \mathrm{RH})$ was tested every two days for 10 days, and a minimal variation in the response, $\Delta \mathrm{F}$, appeared at different humidity levels. This obviously means that the HGO\&GO\& $\mathrm{Mg}^{2+}$-based sensor has good stability. 
(a)

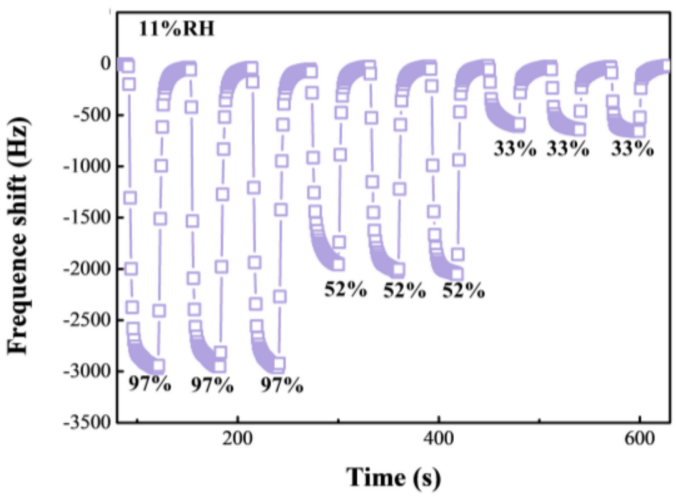

(b)

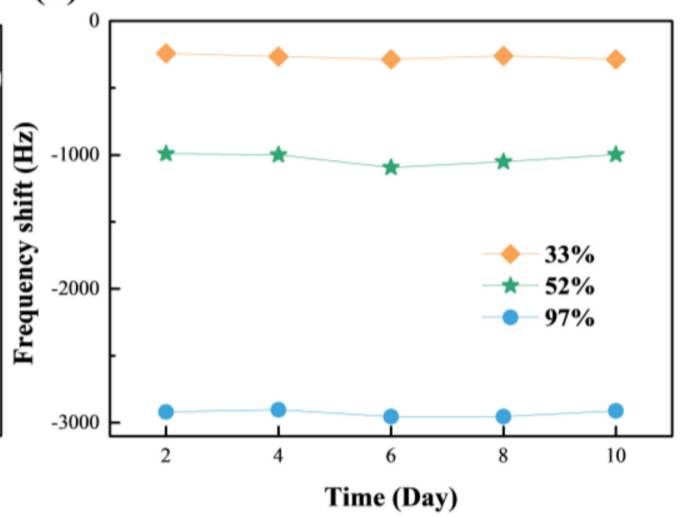

Figure 8. The repeatability (a) and stability (b) test of the HGO\&GO\&Mg ${ }^{2+}$-based QCM humidity sensor.

\subsection{The Mechanism of Humidity Sensing}

According to the aforementioned experimental results, the humidity-sensing performance of the HGO\&GO\& $\mathrm{Mg}^{2+}$-based sensor represents a remarkable enhancement compared with that of GO and HGO. Previous work [20] has reported the interlayer spacing of GOM under relative humidity from $0 \%$ to $100 \%$. Interlayer spacing enlarges with increased humidity. However, even if the $\mathrm{RH}$ reaches $100 \%$, the interlayer spacing of GO is approximately $3 \AA$ larger than that in the case of $0 \% \mathrm{RH}$. Compared with the XRD results in this work, the introduction of $\mathrm{Mg}^{2+}$ can further enlarge the interlayer spacing of HGO\&GOM in different humidity states. Moreover, the interlayer spacing at $97 \% \mathrm{RH}$ is $\sim 4.2 \AA$ larger than that at $11 \% \mathrm{RH}$, which means that HGO\&GO\& $\mathrm{Mg}^{2+}$ can attract and hold more water molecules. Compared with that of GO or HGO, the reason why the humidity-sensing performance of the HGO\&GO\& $\mathrm{Mg}^{2+}$-based sensor represents a remarkable enhancement can be summarized by four aspects:

1. The introduction of magnesium ions can increase the interlayer spacing of GOMs, which is beneficial for attracting and holding more water molecules. This can be proven by XRD results.

2. $\mathrm{Mg}^{2+}$ can prevent the swelling of GOMs [19], which is helpful for decreasing humidity hysteresis.

3. $\mathrm{Mg}^{2+}$ has a certain degree of water-absorption capacity [35-37]. More water molecules can be introduced into GOMs by evenly distributed magnesium ions. It is believed that ions with similar properties to magnesium ions can also increase the humiditysensing performance of GO films.

4. For the composite structure of GO and HGO, on one hand, a large number of oxygencontaining groups in HGO provides many adsorption sites for water molecules; on the other hand, a large number of $\mathrm{sp}^{2}$ hydrophobic regions in the large layer of $\mathrm{GO}$ is conducive to the rapid transmission of water molecules inside the membrane. These are both conducive to improving humidity-sensing performance. In short, a mixed structure of GO and HGO has the ability to balance response sensitivity and response/recovery time.

\section{Conclusions}

In summary, the humidity-sensing properties of GO-based humidity sensors can be significantly enhanced by introducing $\mathrm{Mg}^{2+}$ and a reasonable structural design. The obtained HGO\&GO\& $\mathrm{Mg}^{2+}$ sensor exhibits a high response-frequency shift $(34.3 \mathrm{~Hz} / \% \mathrm{RH})$, short response/recovery times (7 s/6 s), low humidity hysteresis (3.2\%) from $11 \% \mathrm{RH}$ to $97 \% \mathrm{RH}$ and good repeatability/stability. These two improved strategies are based on the fact that $\mathrm{Mg}^{2+}$ not only expands the interlayer spacing of GOMs but also attracts more water molecules into the interior of GOMs, while the unique structure composed 
of HGO and GO still ensures a rapid response/recovery time when humidity sensitivity is vastly improved. Most importantly, the findings in this work contribute to further understanding of the transport mechanism of water molecules in GOMs, which promotes the application of not only QCM humidity materials but also fuel-cell, water-desalination and nanofluidic devices.

Author Contributions: Conceptualization and investigation, L.Z., B.P. and R.Y.; experiment, R.Y.; validation, L.Z. and B.P.; data curation, R.Y., L.C., Y.Z., D.N. and B.P.; writing-original draft preparation, R.Y.; writing—review and editing, L.Z.; project administration, L.Z.; funding acquisition, L.Z. All authors have read and agreed to the published version of the manuscript.

Funding: This research was funded by the National Natural Science Foundation of China (11834018, 11922410).

Institutional Review Board Statement: Not applicable.

Informed Consent Statement: Not applicable.

Data Availability Statement: The data presented in this study are available on request from the corresponding author.

Conflicts of Interest: The authors declare no conflict of interest.

\section{References}

1. Rechenbach, T.; Schramm, U.; Boeker, P.; Horner, G.; Roesky, C.; Trepte, J.; Winter, S.; Pollex, R.; Bargon, J.; Weber, E.; et al. A humidity-independent ammonia sensor based on a quartz microbalance: A test under agricultural conditions. Sens. Actuators $B$ Chem. 1999, 57, 255-260. [CrossRef]

2. Onibonoje, M.O.; Nwulu, N.I.; Bokoro, P.N. A wireless sensor network system for monitoring environmental factors affecting bulk grains storability. J. Food Process Eng. 2019, 42. [CrossRef]

3. Thebo, K.H.; Qian, X.; Zhang, Q.; Chen, L.; Cheng, H.-M.; Ren, W. Highly stable graphene-oxide-based membranes with superior permeability. Nat. Commun. 2018, 9, 1-8. [CrossRef] [PubMed]

4. $\quad \mathrm{Bi}, \mathrm{S} . ; \mathrm{Hou}, \mathrm{L} . ; \mathrm{Lu}, \mathrm{Y}$. An integrated wearable strain, temperature and humidity sensor for multifunctional monitoring. Compos. Part A: Appl. Sci. Manuf. 2021, 149, 106504. [CrossRef]

5. Peng, B.; Zhao, Y.; Nie, D.; Yi, R.; Chen, L.; Zhang, L. Selective transport properties of graphene oxide membranes for various cations observed in situ using quartz crystal microbalance. Appl. Surf. Sci. 2020, 541, 148502. [CrossRef]

6. Singh, E.; Meyyappan, M.; Nalwa, H.S. Flexible Graphene-Based Wearable Gas and Chemical Sensors. ACS Appl. Mater. Interfaces 2017, 9, 34544-34586. [CrossRef]

7. Zheng, S.; Tu, Q.; Urban, J.J.; Li, S.; Mi, B. Swelling of Graphene Oxide Membranes in Aqueous Solution: Characterization of Interlayer Spacing and Insight into Water Transport Mechanisms. ACS Nano 2017, 11, 6440-6450. [CrossRef]

8. Hampitak, P.; Melendrez, D.; Iliut, M.; Fresquet, M.; Parsons, N.; Spencer, B.; A Jowitt, T.; Vijayaraghavan, A. Protein interactions and conformations on graphene-based materials mapped using a quartz-crystal microbalance with dissipation monitoring (QCM-D). Carbon 2020, 165, 317-327. [CrossRef]

9. Lesniak, A.; Salvati, A.; Santos-Martinez, M.J.; Radomski, M.W.; Dawson, K.A.; Åberg, C. Nanoparticle Adhesion to the Cell Membrane and Its Effect on Nanoparticle Uptake Efficiency. J. Am. Chem. Soc. 2013, 135, 1438-1444. [CrossRef] [PubMed]

10. Tang, K.; Chen, X.; Ding, X.; Yu, X.; Yu, X. MoS2/Graphene Oxide/C60-OH Nanostructures Deposited on a Quartz Crystal Microbalance Transducer for Humidity Sensing. ACS Appl. Nano Mater. 2021, 4, 10, 10810-10818. [CrossRef]

11. Zhang, D.; Song, X.; Wang, Z.; Chen, H. Ultra-highly sensitive humidity sensing by polydopamine/graphene oxide nanostructure on quartz crystal microbalance. Appl. Surf. Sci. 2020, 538, 147816. [CrossRef]

12. Yuan, Z.; Tai, H.L.; Ye, Z.B.; Liu, C.H.; Xie, G.Z.; Du, X.S.; Jiang, Y.D. Novel highly sensitive QCM humidity sensor with low hysteresis based on graphene oxide (GO)/poly(ethyleneimine) layered film. Sens. Actuators B Chem. 2016, 234, 145-154. [CrossRef]

13. Zhang, D.; Wang, D.; Li, P.; Zhou, X.; Zong, X.; Dong, G. Facile fabrication of high-performance QCM humidity sensor based on layer-by-layer self-assembled polyaniline/graphene oxide nanocomposite film. Sens. Actuators B Chem. 2018, 255, 1869-1877. [CrossRef]

14. Yuan, Z.; Tai, H.; Bao, X.; Liu, C.; Ye, Z.; Jiang, Y. Enhanced humidity-sensing properties of novel graphene oxide/zinc oxide nanoparticles layered thin film QCM sensor. Mater. Lett. 2016, 174, 28-31. [CrossRef]

15. Zhu, Y.; Murali, S.; Cai, W.; Li, X.; Suk, J.W.; Potts, J.R.; Ruoff, R.S. Graphene and Graphene Oxide: Synthesis, Properties, and Applications. Adv. Mater. 2010, 22, 3906-3924. [CrossRef] [PubMed]

16. Duan, Z.; Jiang, Y.; Tai, H. Recent advances in humidity sensors for human body related humidity detection. J. Mater. Chem. C 2021, 9, 14963-14980. [CrossRef]

17. Xu, J.; Bertke, M.; Wasisto, H.S.; Peiner, E. Piezoresistive microcantilevers for humidity sensing. J. Micromech. Microeng. 2019, 29, 053003. [CrossRef] 
18. Fauzi, F.; Rianjanu, A.; Santoso, I.; Triyana, K. Gas and humidity sensing with quartz crystal microbalance (QCM) coated with graphene-based materials - A mini review. Sens. Actuators A: Phys. 2021, 330, 112837. [CrossRef]

19. Chen, L.; Shi, G.; Shen, J.; Peng, B.; Zhang, B.; Wang, Y.; Bian, F.; Wang, J.; Li, D.; Qian, Z.; et al. Ion sieving in graphene oxide membranes via cationic control of interlayer spacing. Nature 2017, 550, 380-383. [CrossRef]

20. Abraham, J.; Vasu, K.S.; Williams, C.D.; Gopinadhan, K.; Su, Y.; Cherian, C.T.; Dix, J.; Prestat, E.; Haigh, S.J.; Grigorieva, I.V.; et al. Tunable sieving of ions using graphene oxide membranes. Nat. Nanotechnol. 2017, 12, 546-550. [CrossRef]

21. Khan, S.A.; Saqib, M.; Rehman, M.M.; Mutee Ur Rehman, H.M.; Rahman, S.A.; Yang, Y.; Kim, S.; Kim, W.-Y. A Full-Range Flexible and Printed Humidity Sensor Based on a Solution-Processed P(VDF-TrFE)/Graphene-Flower Composite. Nanomaterials 2021, 11, 1915. [CrossRef]

22. Saqib, M.; Khan, S.A.; Mutee Ur Rehman, H.M.; Yang, Y.; Kim, S.; Rehman, M.M.; Young Kim, W. High-Performance Humidity Sensor Based on the Graphene Flower/Zinc Oxide Composite. Nanomaterials 2021, 11, 242. [CrossRef]

23. Yao, Y.; Huang, X.-H.; Zhang, B.-Y.; Zhang, Z.; Hou, D.; Zhou, Z.-K. Facile fabrication of high sensitivity cellulose nanocrystals based QCM humidity sensors with asymmetric electrode structure. Sens. Actuators B Chem. 2019, 302, 127192. [CrossRef]

24. Yu, X.L.; Chen, X.D.; Ding, X.; Chen, X.P.; Yu, X.; Zhao, X. High-sensitivity and low-hysteresis humidity sensor based on hydrothermally reduced graphene oxide/nanodiamond. Sens. Actuators B Chem. 2019, 283, 761-768. [CrossRef]

25. Dreyer, D.R.; Park, S.; Bielawski, C.W.; Ruoff, R.S. The chemistry of graphene oxide. Chem. Soc. Rev. 2010, 39, 228-240. [CrossRef]

26. Zhang, L.; Dai, F.; Yi, R.; He, Z.; Wang, Z.; Chen, J.; Liu, W.; Xu, J.; Chen, L. Effect of physical and chemical structures of graphene oxide on water permeation in graphene oxide membranes. Appl. Surf. Sci. 2020, 520, 146308. [CrossRef]

27. Zhao, G.; Zhu, H. Cation- $\pi$ Interactions in Graphene-Containing Systems for Water Treatment and Beyond. Adv. Mater. 2020, 32, 1905756. [CrossRef] [PubMed]

28. Yi, R.; Xia, X.; Yang, R.; Yu, R.; Dai, F.; Chen, J.; Liu, W.; Wu, M.; Xu, J.; Chen, L. Selective reduction of epoxy groups in graphene oxide membrane for ultrahigh water permeation. Carbon 2020, 172, 228-235. [CrossRef]

29. O'Brien, F.E.M. The Control of Humidity by Saturated Salt Solutions. J. Sci. Instrum. 1948, 25, 73-76. [CrossRef]

30. Zhang, C.; Dabbs, D.M.; Liu, L.-M.; Aksay, I.A.; Car, R.; Selloni, A. Combined Effects of Functional Groups, Lattice Defects, and Edges in the Infrared Spectra of Graphene Oxide. J. Phys. Chem. C 2015, 119, 18167-18176. [CrossRef]

31. Bagri, A.; Mattevi, C.; Acik, M.; Chabal, Y.J.; Chhowalla, M.; Shenoy, V.B. Structural evolution during the reduction of chemically derived graphene oxide. Nat. Chem. 2010, 2, 581-587. [CrossRef] [PubMed]

32. Jeong, H.-K.; Lee, Y.P.; Lahaye, R.J.W.E.; Park, M.-H.; An, K.H.; Kim, I.J.; Yang, C.-W.; Park, C.Y.; Ruoff, A.R.S.; Lee, Y.H. Evidence of Graphitic AB Stacking Order of Graphite Oxides. J. Am. Chem. Soc. 2008, 130, 1362-1366. [CrossRef]

33. Yi, R.; Yang, R.; Yu, R.; Lan, J.; Chen, J.; Wang, Z.; Chen, L.; Wu, M. Ultrahigh permeance of a chemical cross-linked graphene oxide nanofiltration membrane enhanced by cation- $\pi$ interaction. RSC Adv. 2019, 9, 40397-40403. [CrossRef]

34. Lee, S.-W.; Choi, B.I.; Kim, J.C.; Woo, S.-B.; Kim, Y.-G. Reducing individual difference and temperature dependency of QCM humidity sensors based on graphene oxides through normalization of frequency shifts. Sens. Actuators B Chem. 2020, 313, 128043. [CrossRef]

35. Peschke, M.; Blades, A.T.; Kebarle, P. Hydration Energies and Entropies for Mg2+, Ca2+, Sr2+, and Ba2+ from Gas-Phase Ion-Water Molecule Equilibria Determinations. J. Phys. Chem. A 1998, 102, 48, 9978-9985. [CrossRef]

36. Bock, C.W.; Katz, A.K.; Glusker, J.P. Hydration of Zinc Ions: A Comparison with Magnesium and Beryllium Ions. J. Am. Chem. Soc. 1995, 117, 3754-3765. [CrossRef]

37. Neely, J.; Connick, R. Rate of water exchange from hydrated magnesium ion. J. Am. Chem. Soc. 1970, 92, 3476-3478. [CrossRef]

38. Cohen-Tanugi, D.; Grossman, J.C. Water Desalination across Nanoporous Graphene. Nano Lett. 2012, 12, 3602-3608. [CrossRef]

39. Nair, R.R.; Wu, H.A.; Jayaram, P.N.; Grigorieva, I.V.; Geim, A.K. Unimpeded Permeation of Water Through Helium-Leak-Tight Graphene-Based Membranes. Science 2012, 335, 442-444. [CrossRef] [PubMed]

40. Mi, B. Graphene Oxide Membranes for Ionic and Molecular Sieving. Science 2014, 343, 740-742. [CrossRef]

41. Wang, S.; Xie, G.; Su, Y.; Su, L.; Zhang, Q.; Du, H.; Tai, H.; Jiang, Y. Reduced graphene oxide-polyethylene oxide composite films for humidity sensing via quartz crystal microbalance. Sens. Actuators B Chem. 2017, 255, 2203-2210. [CrossRef]

42. Ding, X.; Chen, X.; Chen, X.; Zhao, X.; Li, N. A QCM humidity sensor based on fullerene/graphene oxide nanocomposites with high quality factor. Sens. Actuators B Chem. 2018, 266, 534-542. [CrossRef]

43. Zhang, D.; Wang, D.; Zong, X.; Dong, G.; Zhang, Y. High-performance QCM humidity sensor based on graphene oxide/tin oxide/polyaniline ternary nanocomposite prepared by in-situ oxidative polymerization method. Sens. Actuators B Chem. 2018, 262, 531-541. [CrossRef]

44. Lee, S.-W.; Choi, B.I.; Kim, J.C.; Woo, S.-B.; Kim, Y.-G.; Yoo, J.; Seo, Y.-S. Reduction and compensation of humidity measurement errors at cold temperatures using dual QCM humidity sensors based on graphene oxides. Sens. Actuators B Chem. 2018, 284, 386-394. [CrossRef]

45. Rianjanu, A.; Julian, T.; Hidayat, S.N.; Yulianto, N.; Majid, N.; Syamsu, I.; Wasisto, H.S.; Triyana, K. Quartz crystal microbalance humidity sensors integrated with hydrophilic polyethyleneimine-grafted polyacrylonitrile nanofibers. Sens. Actuators B Chem. 2020, 319, 128286. [CrossRef] 
46. Li, R.; Fan, Y.; Ma, Z.; Zhang, D.; Liu, Y.; Xu, J. Controllable preparation of ultrathin MXene nanosheets and their excellent QCM humidity sensing properties enhanced by fluoride doping. Microchim. Acta 2021, 188, 1-11. [CrossRef]

47. Liu, X.; Zhang, D.; Wang, D.; Li, T.; Song, X.; Kang, Z. A humidity sensing and respiratory monitoring system constructed from quartz crystal microbalance sensors based on a chitosan/polypyrrole composite film. J. Mater. Chem. A 2021, 9, 14524-14533. [CrossRef] 